\title{
Development of Ti-V-Mo Complex Microalloyed Hot-Rolled 900-MPa-Grade High-Strength Steel
}

\author{
Ke Zhang $\cdot$ Zhao-Dong Li $\cdot$ Xin-Jun Sun $\cdot$ Qi-Long Yong $\cdot$ Jun-Wei Yang $\cdot$ Yuan-Mei Li $\cdot$ Pei-Lin Zhao
}

Received: 2 September 2014/Revised: 13 November 2014/Published online: 4 March 2015

(C) The Chinese Society for Metals and Springer-Verlag Berlin Heidelberg 2015

\begin{abstract}
A new Ti-V-Mo complex microalloyed hot-rolled high-strength steel sheet was developed by controlling a thermo-mechanical controlled processing (TMCP) schedule, in particular with variants in coiling temperature. The effects of coiling temperature (CT) on various hardening mechanisms and mechanical properties of Ti-V-Mo complex microalloyed high-strength low-alloy steels were investigated. The results revealed that the steels are mainly strengthened by a combined effect of ferrite grain refinement hardening and precipitation hardening. The variation in simulated coiling temperature causes a significant difference in strength, which is mainly attributed to different precipitation hardening increment contributions. When the $\mathrm{CT}$ is $600{ }^{\circ} \mathrm{C}$, the experimental steel has the best mechanical properties: ultimate tensile strength (UTS) $1000 \mathrm{MPa}$, yield strength (YS) $955 \mathrm{MPa}$ and elongation (EL) 17\%. Moreover, about 82 wt\% of the total precipitates are nano-sized carbide particles with diameter of 1-10 nm, which is randomly dispersed in the ferrite matrix. The nano-sized carbide particles led to a strong precipitation hardening increment up to $310 \mathrm{MPa}$.
\end{abstract}

\section{KEY WORDS: Hot-rolled high-strength steel; Strengthening mechanism; Nano-sized carbide; Precipitation hardening; Coiling temperature}

\section{Introduction}

In view of the limited materials resources and energy supply available together with serious environment impact

Available online at http://link.springer.com/journal/40195

K. Zhang $(\bowtie) \cdot$ Y.-M. Li

Department of Materials Science and Engineering, Kunming University of Science and Technology, Kunming 650093, China e-mail: huzhude@yeah.net

K. Zhang · Z.-D. Li $\cdot$ X.-J. Sun · Q.-L. Yong $\cdot$ J.-W. Yang · Y.-M. Li

Central Iron and Steel Research Institute, Beijing 100081, China

J.-W. Yang

Department of Materials Science and Engineering, Huazhong

University of Science and Technology, Wuhan 430074, China

P.-L. Zhao

R\&D Center, Laiwu Iron and Steel Group Co Ltd, Laiwu 271104, China concerns at the present time, the development of highstrength low-alloy steels (HSLA) have attracted a great deal of attention from researchers. As we know, most traditional high-strength steels have been developed based on martensitic and bainitic structures with high levels of carbon or high alloy additions. However, these alloys are facing many severe problems, including low ductility and toughness, poor weldability, fabrication-size limitation, as well as high production cost; all of these resulted in slowdown of the economic and national-defense developments [1]. Thus, it is imperative to speed up the development of high-strength steels with excellent mechanical and metallurgical properties as well as low manufacturing cost [2,3].

HSLA steels are known to be strengthened by grain refinement, solid solution hardening and precipitation hardening. Previous researchers have focused mainly on strengthening by grain refinement using the TMCP schedule [4-8]. In recent work conducted at JFE steel [9], tensile strength of up to $780 \mathrm{MPa}$ with EL 24\% has been achieved 
in Ti- and Mo-bearing HSLA steel sheets by producing microstructures that consist of a ferrite matrix with nanometer-sized carbides, and precipitation hardening due to the nano-sized carbides in these alloys has been estimated to be approximately $300 \mathrm{MPa}$. From then on, the research and development of Ti-Mo complex microalloyed hot-rolled high-strength steels depended on ferrite refinement, and precipitation hardening by nano-sized carbide precipitates using TMCP has drawn significant attention. Complex carbides formed by Ti and Mo in HSLA steels are more efficient and can strongly maintain nanometer-scaled sizes for strengthening; many studies on the strengthening HSLA steels based on the formation of complex Ti carbides containing Mo have been reported [9-17]. However, the YS of most Ti and Mo complex microalloyed hot-rolled highstrength steels are $<900 \mathrm{MPa}$; this has necessitated the demand of developing high strength (YS higher than $900 \mathrm{MPa}$ ) with high EL (>15\%) to promote good forming operation to be carried out.

$\mathrm{V}, \mathrm{Nb}$ and $\mathrm{Ti}$ are often used as the addition of microalloying elements in high-strength steels, but the solid solution products of $\mathrm{VC}$ or $\mathrm{V}(\mathrm{N}, \mathrm{C})$ in austenite are the largest of all; therefore, $\mathrm{V}$ is the most ideal element used as precipitation strengthening. In addition, compared with the Ticontaining steels, the mechanical performance of V-containing steels is less volatile. On one hand, the $\mathrm{V}$ addition in the Ti-Mo- bearing steel brings three advantages: (1) increasing the volume fraction of precipitates; (2) refining the microstructure and precipitates to a smaller scale [18]; and (3) the complex precipitates ( $\mathrm{Ti}, \mathrm{V}, \mathrm{Mo}) \mathrm{C}$ have extremely higher thermal stability than $(\mathrm{Ti}, \mathrm{Mo}) \mathrm{C}$ [19]. On the other hand, to our knowledge, the research and development of $\mathrm{V}$ addition in Ti-Mo microalloyed hot-rolled HSLA steel sheet consisting of ferrite and nano-sized carbides have rarely touched upon. Consequently, it has an important theoretical meaning and a wide practical value to develop and research the Ti-V-Mo complex microalloyed hot-rolled steel with 900 MPa YS by TMCP schedule.

In this study, a novel Ti-V-Mo hot-rolled high-strength steel sheet was developed by controlling TMCP schedule. The contributions of various strengthening factors at different CTs of the steel were calculated and compared, and the effects of CT on the microstructure evolution and mechanical properties were examined. The present work is expected to provide a theoretical basis and a practical significance for the development of $\mathrm{Ti}-\mathrm{V}-\mathrm{Mo}$ complex microalloyed hot-rolled high-strength steel.

\section{Experimental}

The chemical composition (wt $\%$ ) of the as-received steel used in this work is $0.09 \mathrm{C}, 0.11 \mathrm{Si}, 1.29 \mathrm{Mn}, 0.27 \mathrm{Cr}$,
$0.093 \mathrm{Ti}, 0.26 \mathrm{Mo}, 0.14 \mathrm{~V}, 0.0022 \mathrm{~S}, 0.0068 \mathrm{P}, 0.0043 \mathrm{~N}$ and balanced by Fe. Figure 1 shows the schematic illustrations of the TMCP schedule. The steel was cast by vacuum induction melting and hot-forged to 30 -mm-thick bars. Hot-forged bars were soaked at $1250{ }^{\circ} \mathrm{C}$ for $1 \mathrm{~h}$, aircooled to the starting rolling temperature $\left(1200{ }^{\circ} \mathrm{C}\right)$, and then were hot-rolled to about $2.5 \mathrm{~mm}$ thick by seven passes rolling. Furthermore, the finishing temperature was controlled at $780{ }^{\circ} \mathrm{C}$. After finishing rolling, they were watercooled to 550,600 and $650{ }^{\circ} \mathrm{C}$ with a cooling rate of $15^{\circ} \mathrm{C} / \mathrm{s}$ and held at the same temperature for $1 \mathrm{~h}$ followed by furnace-cooling to room temperature for hot-coiling simulation, respectively.

Metallographic observation was made by HITACHI S-4300-type scanning electron microscopy (SEM) on the specimens by mechanical polishing and chemical etching with 3\% nital solution. Electron backscattered diffraction (EBSD) was used to identify the size and size distribution of ferrite grain, and for volume fraction of low-angle boundaries (LABs), which is composed of dislocations, a step size of $0.2 \mu \mathrm{m}$ was used. The surface of the test sample was ground on conventional grinding papers and electro-polished using a solution containing $92 \%$ acetic acid and $8 \%$ perchloric acid at room temperature for $10 \mathrm{~s}$, the voltage was $60 \mathrm{~V}$. The EBSD data measured were interpreted by orientation imaging microscopy analysis software. Tensile tests were conducted using a WE-300 machine at room temperature. Test samples with their longitudinal axis aligned parallel to the rolling direction were machined in the gauge section of the test sample with a size of $140 \mathrm{~mm} \times 10 \mathrm{~mm} \times 2 \mathrm{~mm}$. The dislocation density (DSD) was tested by PHILIPS-10XRD which has a Co target, a voltage of $30 \mathrm{keV}$ and a step size of $0.02^{\circ}$. The integral time $1 \mathrm{~s}$ was used when running the XRD [20].

To identify the morphology, size and distribution of precipitates, the thin foils for transmission electron microscopy (TEM) were prepared by twin-jet polishing in the

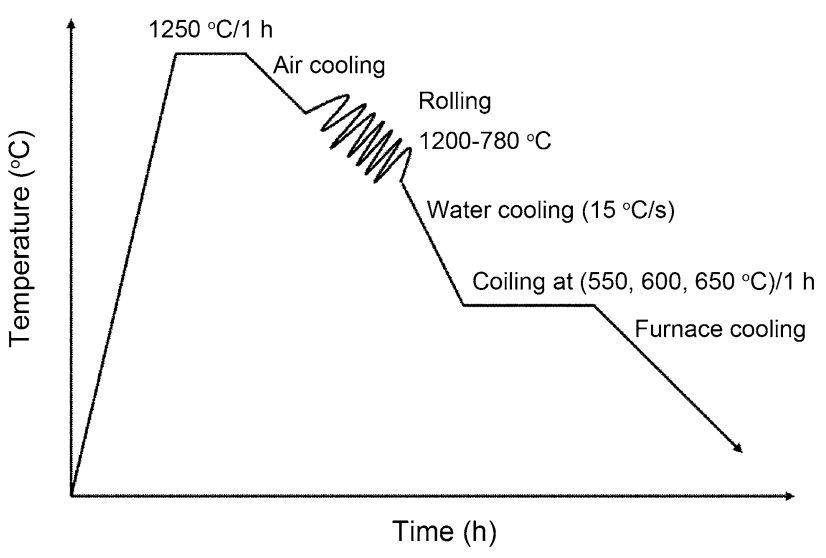

Fig. 1 Schematic illustration describing the TMCP schedule 
electrolyte made of $94 \%$ acetic acid $+6 \%$ perchloric acid. Also, carbon replication technique was used for the observation of the precipitates [9]. During the TEM analysis, the energy dispersive X-ray spectroscopy (EDS) was performed directly on the precipitates. The mass fraction of $M C$ and $M_{3} \mathrm{C}$ phase was measured by using physicalchemical phase analysis [21]. The size distribution of $M C$ precipitates was tested by small-angle X-ray scattering (SAXS). Meanwhile, the phase structures of precipitates were identified by X-ray diffraction (XRD).

\section{Results}

\subsection{Microstructure}

Figure 2 shows the SEM images of the steels processed at different simulated hot-coiling temperature of 550, 600 and $650{ }^{\circ} \mathrm{C}$. It can be seen from Fig. 2 that all the microstructures for different CTs were almost similar, composed of ferrite $(>90 \%)$ and pearlite, only with some difference in the volume fraction of the $M_{3} \mathrm{C}$ (white-etched phase) and the morphology of ferrite. Interestingly, a few $\mathrm{M} / \mathrm{A}$ (martensite/austenite) islands were present at CT of $550{ }^{\circ} \mathrm{C}$, while they were not observed at CT of 600 and $650{ }^{\circ} \mathrm{C}$. Most of $M_{3} \mathrm{C}$ was present at the ferrite grain boundary in a discrete fashion. In addition, the amount of $M_{3} \mathrm{C}$ has the largest value at $\mathrm{CT}$ of $550{ }^{\circ} \mathrm{C}$ and that of $M_{3} \mathrm{C}$ has the minimum value at $\mathrm{CT}$ of $600{ }^{\circ} \mathrm{C}$. With the $\mathrm{CT}$ of $650{ }^{\circ} \mathrm{C}$, the steel is constructed mostly by polygonal ferrite.

Figure 3 shows the microstructures of the steels, taken by EBSD. All steels had quasi-polygonal or polygonal ferrite microstructures in which the dislocations structures, composed of LABs $\left(2^{\circ} \leq \theta<15^{\circ}\right)$, were formed; note that the ferrite grain boundaries correspond to the high-angle grain boundaries (HAGBs) with a high misorientation $\left(\theta \geq 15^{\circ}\right)$. The DSDs of the three samples at different CTs are presented in Table 1.

\subsection{Mechanical Properties}

Mechanical properties, average grain sizes (AVGS) and DSDs of the samples with respect to different CTs are tabulated in Table 1. The results revealed that the sample with the highest mass fraction of fine precipitates $(<10 \mathrm{~nm})$ at $600{ }^{\circ} \mathrm{C}$ (Fig. 5) achieved the greatest strength among the three samples. The strength of the developed steel reached the minimum value at the $\mathrm{CT}$ of $550{ }^{\circ} \mathrm{C}$, while the strength of sample $650{ }^{\circ} \mathrm{C}$ was the middle one among these of the three samples. However, the ELs of the three samples were comparable to each other. The average ferrite grain size of the three samples did not change much, and the minimum size was about $2.32 \mu \mathrm{m}$ at $\mathrm{CT}$ of $600{ }^{\circ} \mathrm{C}$. This implies that the values of grain refinement hardening were close to each other for the steel with different CTs. The effects of grain refinement on the strengthening of the steels were quantified using the measured average size in Table 1 and would be evaluated in the Discussion section compared with other strengthening mechanisms.

\subsection{Precipitation Phase Analysis}

In order to further understand the effect of the size, component and distribution of the precipitates on the mechanicals of the tested steels, the results of TEM observation are shown in Fig. 4. It can be found that the precipitated carbides, having a particle size range from 1 to $10 \mathrm{~nm}$ in diameter, were uniformly distributed in the ferrite matrix at CT of $600{ }^{\circ} \mathrm{C}$ (Fig. 4d-f). The nano-sized carbide particles randomly dispersed in the ferrite matrix are attributed mainly to serve deformation at high temperature and low isothermal holding temperature [22]. In addition, detailed observations show that a few particles with diameters of 1-10 nm were distributed in the grain boundary (Fig. 4b). The EDS analysis of these precipitations reveals that they are (Ti, V, Mo) C particles (Fig. 4c). According to
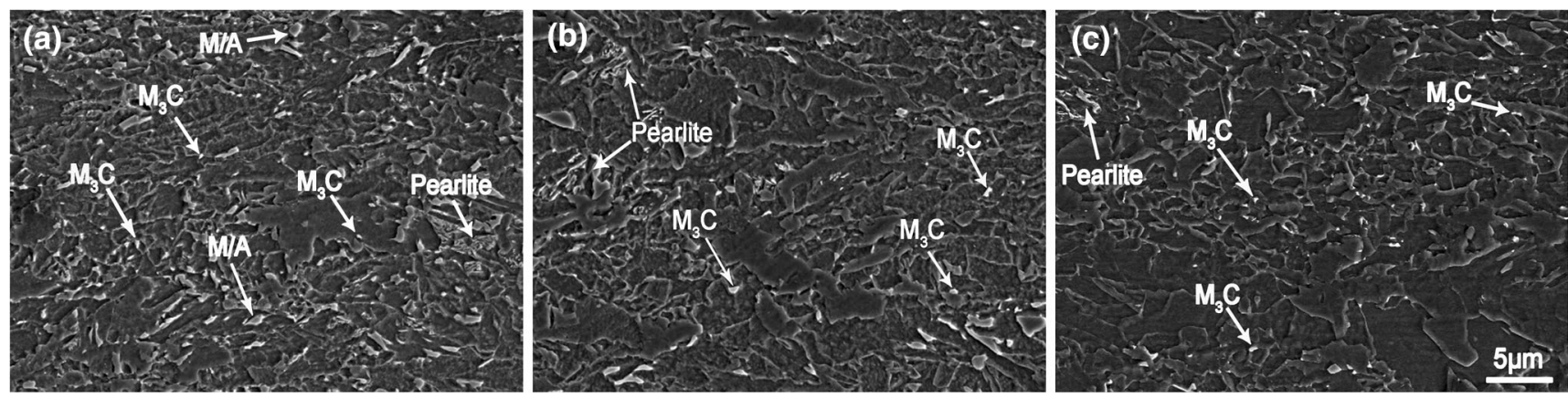

Fig. 2 SEM images showing microstructures of the samples after coiling simulation at different CTs: a $550{ }^{\circ} \mathrm{C}$; b $600{ }^{\circ} \mathrm{C}$; $\mathbf{c} 650{ }^{\circ} \mathrm{C}$ 

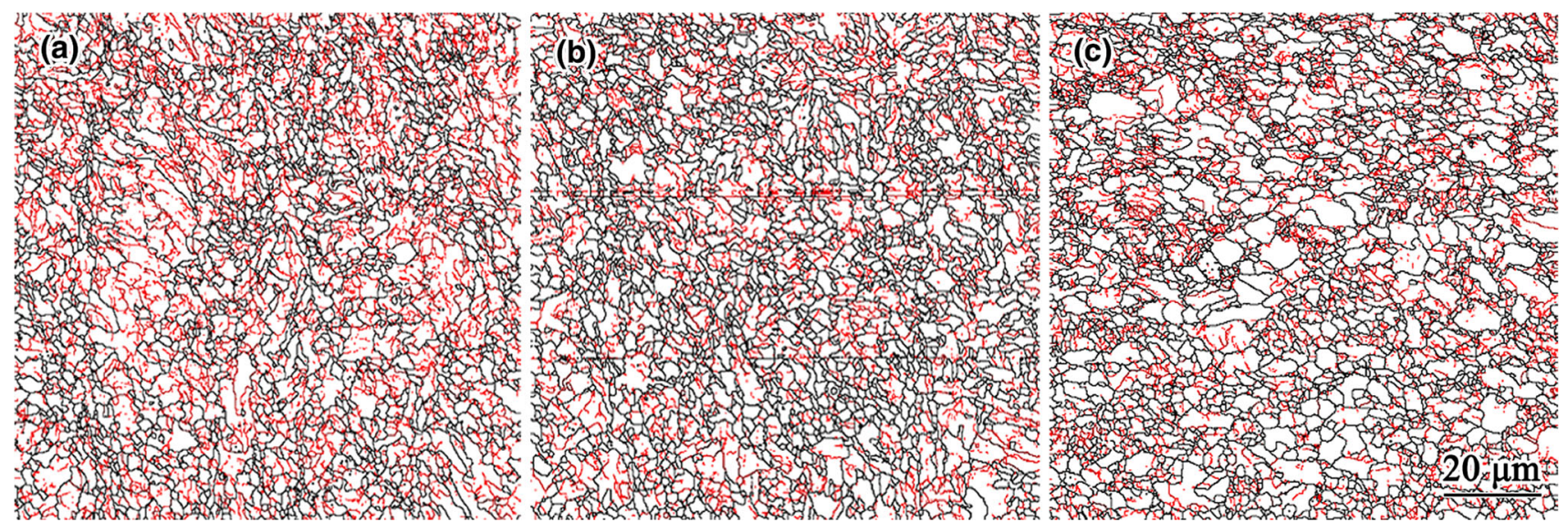

Fig. 3 Microstructures of the samples after coiling simulation at $550{ }^{\circ} \mathrm{C} \mathrm{a}, 600{ }^{\circ} \mathrm{C} \mathbf{b}, 650{ }^{\circ} \mathrm{C} \mathbf{c}$, where black and red lines indicate the high misorientation angle boundaries $\left(\theta \geq 15^{\circ}\right)$ and low misorientation angle boundaries $\left(2^{\circ} \leq \theta<15^{\circ}\right)$, respectively

Refs. [14, 23], these nano-sized carbides with complex compositions have an excellent thermal stability and can maintain their tiny sizes during coiling process. The average size of precipitates in the sample with CT of $600{ }^{\circ} \mathrm{C}$ is the smallest one of the three samples. The larger size of precipitates for the sample with $\mathrm{CT}$ of $650{ }^{\circ} \mathrm{C}$ in comparison with that for the sample with $\mathrm{CT}$ of $600{ }^{\circ} \mathrm{C}$ due to the coarsening of precipitates at higher $\mathrm{CT}$ can be observed in Fig. $4 \mathrm{e}, \mathrm{f}$.

Table 2 shows the results of quantitative analysis of the precipitates of samples. It can be found that the higher the $\mathrm{CT}$, the higher amount of $M \mathrm{C}$ phase. In addition, the amount of $M_{3} \mathrm{C}$ obtained was achieved the minimum value when $\mathrm{CT}$ was $600{ }^{\circ} \mathrm{C}$.

Figure 5 presents the mass fraction of $M C$ precipitates distributed in different size intervals. From Fig. 5, it can be seen that when CT was $600{ }^{\circ} \mathrm{C}$, the sample has a strong peak in the diameter of $1-10 \mathrm{~nm}$ which occupies $82 \mathrm{wt} \%$ of the precipitates. Nevertheless, when CT was 650 and $550{ }^{\circ} \mathrm{C}$, precipitates in the diameter from 1 to $10 \mathrm{~nm}$ occupy $41.8 \mathrm{wt} \%$ and $29.9 \mathrm{wt} \%$, respectively. This order is in agreement with the average size of the precipitates of the three samples shown in Fig. 4d-f. It can be concluded that the mass fraction of precipitates $(<10 \mathrm{~nm})$ was significantly dependent on the CT.

\section{Discussion}

\subsection{Quantification of the Contribution from Various Hardening Factors}

The relationship between YS and microstructure to analyze the strengthening mechanism can be predicted by the following equation: $\sigma_{\mathrm{y}}=\sigma_{0}+\sigma_{\mathrm{s}}+\sigma_{\mathrm{g}}+\sigma_{\mathrm{p}}+\sigma_{\mathrm{d}}$

where $\sigma_{0}$ is the ferrite stress, which has the value of $48 \mathrm{MPa}$ for the ferrite matrix $[9,24], \sigma_{\mathrm{s}}$ is the solid solution stress due to solute elements, $\sigma_{\mathrm{g}}$ is the grain refinement hardening hardness in a polycrystalline steel, $\sigma_{\mathrm{p}}$ is the precipitation hardening stress and $\sigma_{\mathrm{d}}$ is the dislocation hardening stress, caused by the interaction of dislocations.

According to Yong et al. [25], solid solution hardening stress $\sigma_{\mathrm{s}}$ can be evaluated by the following equation:

$$
\begin{aligned}
\sigma_{\mathrm{s}}= & 4570[\mathrm{C}]+3750[\mathrm{~N}]+37[\mathrm{Mn}]+83[\mathrm{Si}]+470[\mathrm{P}]+11[\mathrm{Mo}] \\
& +80.5[\mathrm{Ti}]+2.9[\mathrm{~V}]-30[\mathrm{Cr}],
\end{aligned}
$$

where $[X](X=\mathrm{C}, \mathrm{N}, \mathrm{Mn} \ldots)$ represents the mass fraction of the element $X$ in ferrite. For a microalloyed steel, it can be seen that $\mathrm{Si}$ and $\mathrm{P}$ are all in solution. In this work, $[N]=0$ since all the nitrogen were made the large TiN. Meanwhile, the mass fractions of other elements formed in $M C$ and $M_{3} \mathrm{C}$ particles are shown in Table 2. The calculated values of different stresses for the samples with different CTs are shown in Table 3.

Grain refinement hardening stress $\sigma_{\mathrm{g}}$ can be expressed using the Hall-Petch relation:

$\sigma_{\mathrm{g}}=K_{\mathrm{y}} d_{\mathrm{F}}^{-0.5}$,

where $K_{\mathrm{y}}$ is the constant $\left(0.55 \mathrm{MPa} \mathrm{m}^{0.5}\right.$ for HSLA steel $[9,24])$ and $d_{\mathrm{F}}$ is the average ferrite grain size $(\mathrm{m})$.

The $\sigma_{\mathrm{g}}$ was calculated to be 341,361 and $347 \mathrm{MPa}$ for the samples with $\mathrm{CT}$ of 550,600 and $650{ }^{\circ} \mathrm{C}$, respectively, as shown in Table 3.

Precipitation hardening stress $\sigma_{\mathrm{p}}$ can be given by the Ashby-Orowan relation [19]:

$\sigma_{\mathrm{p}}=8.995 \times 10^{3} \frac{f^{1 / 2}}{d_{\mathrm{p}}} \ln \left(2.417 d_{\mathrm{p}}\right)$, 
Table 1 Mechanical properties, AVGS, and DSDs of the steel at different CTs

\begin{tabular}{llclll}
\hline $\mathrm{CT}\left({ }^{\circ} \mathrm{C}\right)$ & YS $(\mathrm{MPa})$ & UTS $(\mathrm{MPa})$ & EL $(\%)$ & AVGS $(\mu \mathrm{m})$ & DSD $\left(\mathrm{m}^{-2}\right)$ \\
\hline 550 & 815 & 930 & 17.8 & $2.60(0.9)$ & $2.0054 \times 10^{13}$ \\
600 & 955 & 1000 & 17.0 & $2.32(0.5)$ & $1.5293 \times 10^{13}$ \\
650 & 885 & 959 & 18.5 & $2.50(0.7)$ & $1.5113 \times 10^{13}$ \\
\hline
\end{tabular}

The number in parentheses of the column grain size indicates the standard deviation

where $f$ is the volume fraction of precipitation, $d_{\mathrm{p}}$ is the average diameter of precipitates (nm). First, the contribution of each size of precipitates was calculated using the size distribution data (see Fig. 5) and $\sigma_{\mathrm{p}}$ was calculated by adding square value of them all. The calculated results are listed in Table 3. These characteristics of $\sigma_{\mathrm{p}}$ are consistent well with the characteristics on the mass fraction of $M C$ particles distributed in 1-10 nm. It is noted that the results showing $\sigma_{\mathrm{p}}$ mainly contributed from each size of precipitate, but only fine precipitates $(<10 \mathrm{~nm})$ play a key role in the precipitation hardening and the contribution of large precipitates $(>10 \mathrm{~nm})$ can be negligible [12].

Dislocation hardening stress $\sigma_{\mathrm{d}}$ can be expressed as [26]

$\sigma_{\mathrm{d}}=2 \alpha G b \rho^{1 / 2}$,

where $\alpha$ is the constant depending on the crystal structure $(\sim 0.5), G$ is the shear modulus of $\mathrm{Fe}\left(8.065 \times 10^{4} \mathrm{MPa}\right)$, $b$ is the Burgers vector $(0.246 \mathrm{~nm}$ for bcc phase $[9,24])$, and $\rho$ is the DSD per unit area $\left(\mathrm{m}^{-2}\right)$. As described in Fig. 3, LABs $\left(<15^{\circ}\right)$ are composed of dislocations, and thus, their fraction would be proportional to the DSD, which is listed in Table 1 . The calculated $\sigma_{\mathrm{d}}$ is given in Table 3.

Figure 6 graphically shows the contribution of individual strengthening factors to the YS for the steels. The results revealed that the steels were strengthened mostly by a combined effect of ferrite refinement hardening and precipitation hardening. In addition, it is noted that the experimental results corresponded well with the predictions with Eq. (1), indicating that the analyses on the individual strengthening factors, as described above, are reasonable. When $\mathrm{CT}$ was $600{ }^{\circ} \mathrm{C}$, the sample has the greatest contributions of grain refinement and precipitation hardening, which are 361 and $310 \mathrm{MPa}$, respectively. It is noted that the both mechanisms are in an inverse relationship because they are controlled by the austenite to ferrite transformation characteristic, which is dominated by prior austenite grain structure with dislocation structures inside [27]. This fact indicates that as mechanisms for the material strengthening, simultaneously maximizing both effects is not possible; thus, an optimum TMCP schedule is important for improving the strength of steels. The rolling temperature plays a decisive role in the mechanical properties by significantly affecting the characteristics of grain refinement and precipitation $[27,28]$. For CT of $600{ }^{\circ} \mathrm{C}$, the sum contribution of grain refinement and precipitation hardening increments is high up to $671 \mathrm{MPa}$, which is much higher than that of steel subjected to other TMCP processes $[12,28]$. This reflects that the TMCP used in this work for the developed steel is reasonable and superior. It is the reason why the developed steel coiled at $600{ }^{\circ} \mathrm{C}$ has the greatest YS.

\subsection{Effects of CT on the Microstructure and Mechanical Properties}

According to the results of Table 3, it can be confirmed that the change in YS is mainly caused by the change in precipitation hardening. The diffusion coefficient of carbon atoms and titanium atoms in ferrite is, respectively, expressed as [29]

$D_{\mathrm{C}}=6.2 \times 10^{-3} \exp \left(-\frac{80000}{R T}\right) \quad\left(350-850^{\circ} \mathrm{C}\right)$.

$D_{\mathrm{Ti}}=8.6 \times 10^{-6} \exp \left(-\frac{150000}{R T}\right) \quad\left(690-880^{\circ} \mathrm{C}\right)$.

where $D$ is the diffusion coefficients in $\mathrm{cm}^{2} / \mathrm{s}$, $R=8.314 \mathrm{~J} \mathrm{~mol}^{-1} \mathrm{~K}^{-1}$ is the perfect gas constant and $T$ is the absolute temperature in $\mathrm{K}$.

At the lower CT of $550{ }^{\circ} \mathrm{C}$, the microstructure of steel contains mostly bainitic ferrite, small amounts of pearlite and M/A islands. In alloyed steels, bainitic ferrite can form quickly from $0.5 \mathrm{~s}$ to a couple of seconds in general, which is much rapider than the nucleation of proeutectoid ferrite [19]. However, precipitation nucleation is a kind of diffusion transformation, which relies on diffusion of carbon atoms, titanium atoms and vanadium atoms. Cementite precipitates $\left(M_{3} \mathrm{C}\right)$ always prior to the precipitation of the alloy carbides $(M C)$ [30]. This may be attributed to the special crystallization properties of $M_{3} \mathrm{C}$, and the diffusion speed of carbon is far greater than that of alloy elements like $\mathrm{Ti}$ and $\mathrm{V}$. With $700{ }^{\circ} \mathrm{C}$, for example, diffusion of carbon atoms and titanium atoms is $3.15 \times 10^{-7}$ and $7.63 \times 10^{-14} \mathrm{~cm}^{2} / \mathrm{s}$, respectively. The diffusion coefficient of carbon atoms is significantly higher than that of titanium and vanadium, so the largest quantities of $M_{3} \mathrm{C}$ and smallest quantities of $M \mathrm{C}$ can be obtained for sample with $\mathrm{CT}$ of $550{ }^{\circ} \mathrm{C}$. In addition, a small amount of supercooled 

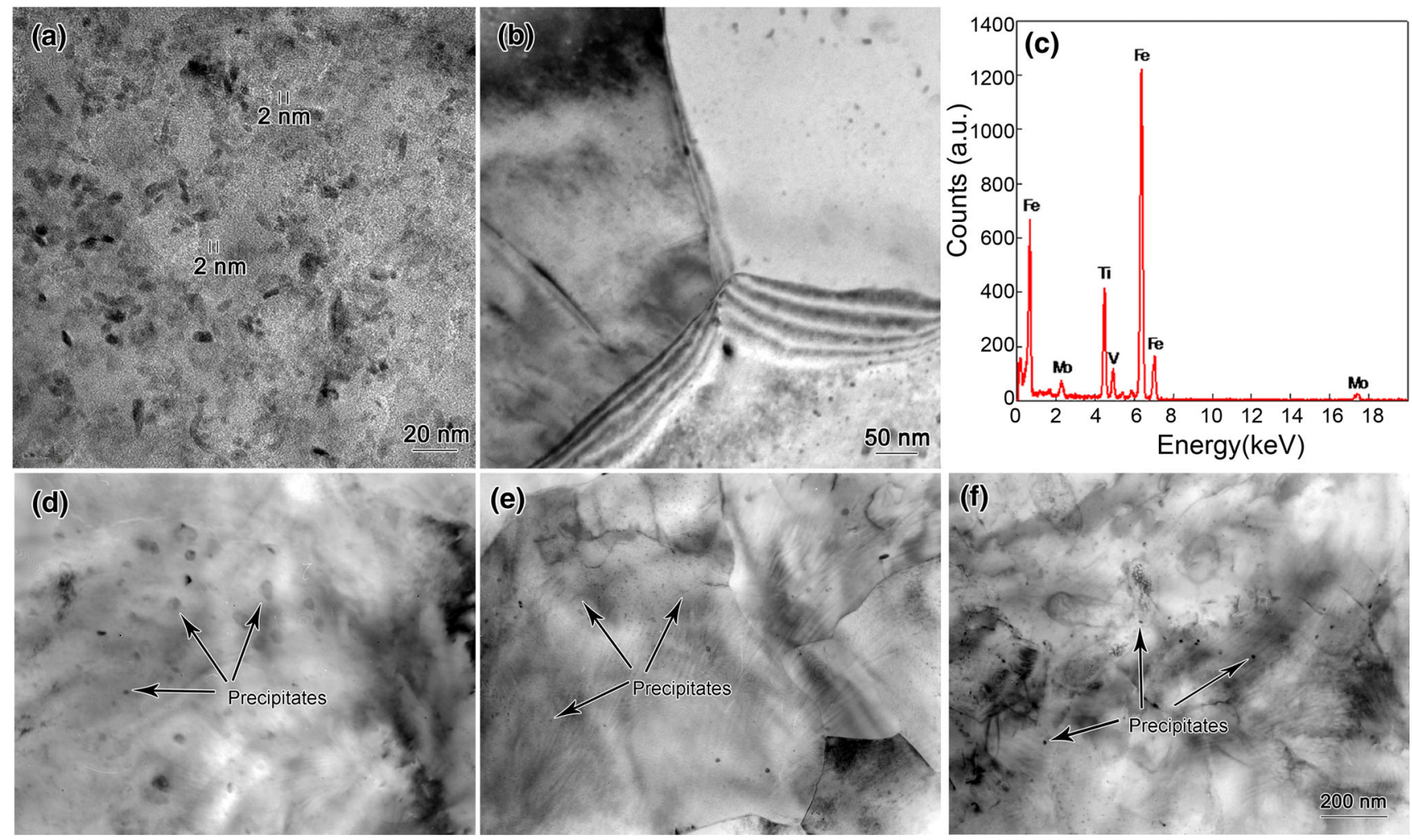

Fig. 4 a TEM image shows the supersaturated precipitations of carbides in the sample coiled at $600{ }^{\circ} \mathrm{C}$; $\mathbf{b}$ TEM image shows the grain boundary with carbides in the sample coiled at $600{ }^{\circ} \mathrm{C}$; $\mathbf{c}$ EDS spectrum of a precipitate in a; d TEM image shows precipitates randomly in the ferrite matrix of the sample coiled at $550{ }^{\circ} \mathrm{C}$; e TEM image shows precipitates randomly in the ferrite matrix of the sample coiled at $600{ }^{\circ} \mathrm{C}$; f TEM image shows precipitates randomly in the ferrite matrix of the sample coiled at $650{ }^{\circ} \mathrm{C}$

austenite transforms into pearlite, and the little remaining supercooled austenite with higher stability transforms into $\mathrm{M} / \mathrm{A}$ island in subsequent cooling.

However, some of the alloying elements still remain in the $\alpha$ solid solution due to the lower CT, so larger solid solution hardening increment about $221 \mathrm{MPa}$ can be obtained at the $\mathrm{CT}$ of $550{ }^{\circ} \mathrm{C}$. The amount of nano-sized precipitates of $M C$ has the minimum value at $\mathrm{CT}$ of $550{ }^{\circ} \mathrm{C}$. Besides, the mass fraction of $M \mathrm{C}$ particles with the size of $1-10 \mathrm{~nm}$ is not high, about $30 \%$ (Fig. 5). Owning to the above reasons, the contribution of precipitation hardening is only around $124 \mathrm{MPa}$, which is the main reason why the steel has the lowest YS at CT of $550{ }^{\circ} \mathrm{C}$.

It has been considered that cementite precipitates by a para-equilibrium state with ferrite matrix at the very stage of tempering [31]. Strong carbide forming elements like Ti and $\mathrm{V}$ are prone to forming $M C$ precipitation due to their diffusivity enhanced at higher CT. This is the reason why the amount of MC increases with the higher of CT. That is to say that the two co-precipitation phases are competing for carbon (Table 2). The ferrite-cementite para-equilibrium state must change the matrix C-content as the CT changes, thus affecting both the volume fraction and average particle size of $M C$ carbide. Meanwhile, it also results in the variation of the contributions of solute solution and precipitation hardening at different CTs (Table 3).

The amount of $M \mathrm{C}$ was larger for sample at $\mathrm{CT}$ of $650{ }^{\circ} \mathrm{C}$ than that for sample at $\mathrm{CT}$ of $600{ }^{\circ} \mathrm{C}$ (Table 2), but its precipitation hardening increment was adversely lower than that of sample at $\mathrm{CT}$ of $600{ }^{\circ} \mathrm{C}$. This is due to the fact that the second particles become coarser as the CT increased, as shown in Fig. 4e, f. Some studies [13, 32] also found that carbide precipitates in ferrite matrix will be coarsened with the annealing temperature increased. The Mo atomic ratio in $M C$ particle increases with increase in $\mathrm{CT}$, which will be beneficial to subsequent precipitation, as shown in Table 2. As pointed out by Jang et al. [23], although the replacement of some of the Ti sub-lattice sites by Mo atoms does not favor energy reduction, it can minimize interfacial energy and maintain better coherency between carbide particles and the ferrite matrix. Therefore, the amount of $M \mathrm{C}$ precipitates increases with increase in CT, specifically about $0.117 \%$ at $550{ }^{\circ} \mathrm{C}, 0.250 \%$ at $600{ }^{\circ} \mathrm{C}$ and $0.341 \%$ at $650{ }^{\circ} \mathrm{C}$ (Table 2). It is clear that the optimum precipitation temperature is $600{ }^{\circ} \mathrm{C}$ for the steel developed (Table 1), and this fact corresponds well with the suitable 
Table 2 Quantitative analysis results of precipitates coiling at different CTs (in wt\%)

\begin{tabular}{|c|c|c|c|c|c|c|c|c|c|c|c|c|}
\hline \multirow[t]{2}{*}{$\overline{\mathrm{CT}}\left({ }^{\circ} \mathrm{C}\right)$} & \multicolumn{5}{|l|}{$M C$} & \multicolumn{7}{|l|}{$M_{3} \mathrm{C}$} \\
\hline & $\mathrm{Ti}$ & Mo & $\mathrm{V}$ & $\mathrm{C}$ & $\sum$ & $\mathrm{Fe}$ & $\mathrm{Mn}$ & $\mathrm{Cr}$ & Mo & V & $\mathrm{C}$ & $\sum$ \\
\hline 550 & 0.034 & 0.041 & 0.023 & 0.019 & 0.117 & 0.378 & 0.054 & 0.021 & 0.042 & 0.012 & 0.035 & 0.542 \\
\hline 600 & 0.064 & 0.085 & 0.060 & 0.041 & 0.250 & 0.079 & 0.010 & 0.013 & 0.025 & 0.009 & 0.030 & 0.166 \\
\hline 650 & 0.062 & 0.130 & 0.095 & 0.054 & 0.341 & 0.168 & 0.030 & 0.010 & 0.029 & 0.010 & 0.017 & 0.264 \\
\hline
\end{tabular}

All the results are with respect to the weight of the whole sample

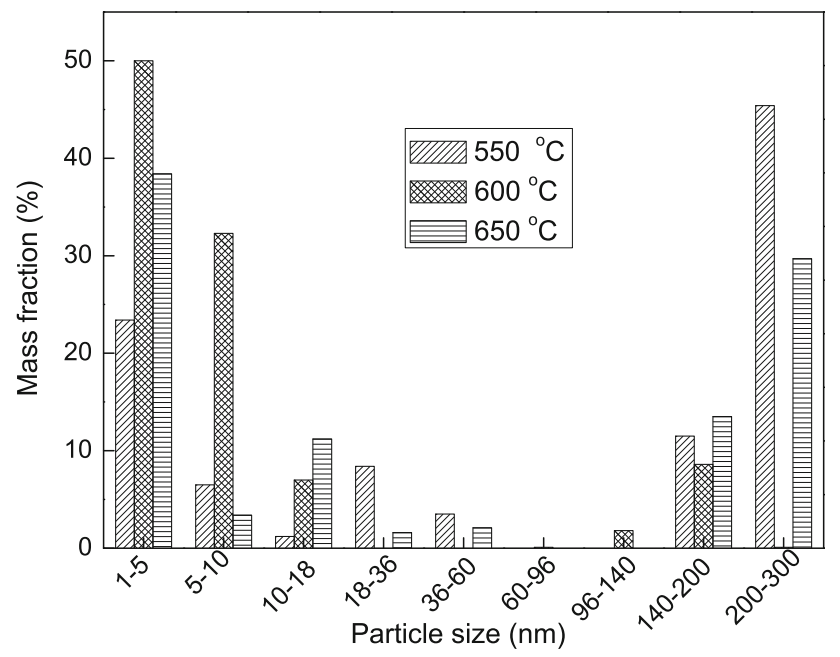

Fig. 5 Mass fraction of $M C$ particles distributed in different size intervals

Table 3 Comparison of YS between experimental results and the predictions with Eq. (1) (in MPa)

\begin{tabular}{llllllll}
\hline $\mathrm{CT}\left({ }^{\circ} \mathrm{C}\right)$ name & $\sigma_{0}$ & $\sigma_{\mathrm{s}}$ & $\sigma_{\mathrm{g}}$ & $\sigma_{\mathrm{p}}$ & $\sigma_{\mathrm{d}}$ & $\sigma_{\text {cal }}$ & $\sigma_{\text {exp }}$ \\
\hline 550 & 48 & 221 & 341 & 124 & 89 & 823 & 815 \\
600 & 48 & 141 & 361 & 310 & 78 & 938 & 955 \\
650 & 48 & 140 & 347 & 263 & 77 & 875 & 885
\end{tabular}

$\sigma_{\text {cal }}=\sigma_{0}+\sigma_{\mathrm{s}}+\sigma_{\mathrm{g}}+\sigma_{\mathrm{p}}+\sigma_{\mathrm{d}}$ is the calculated YS with Eq. (1); $\sigma_{\exp }$ is the experimental YS

CT of $(615 \pm 15){ }^{\circ} \mathrm{C}$ provided by researchers $[11,12]$. Precipitate hardening is caused by the formation of fine carbide particles dispersed in the matrix, at the boundaries and around dislocations [33], as shown in Fig. 4d-f. The nucleation temperature for large amount of precipitates in HSLA steels was believed to be about $600{ }^{\circ} \mathrm{C}$ [34], which is related with the mass fraction of $M C$ precipitates in $1-10 \mathrm{~nm}$ occupied about $82 \%$. Plenty of nano-sized precipitates and larger mass fraction of $M C$ precipitates are the reasons to obtain the largest value about $310 \mathrm{MPa}$ of precipitation hardening. The increment of precipitation hardening of the steel is higher than $276 \mathrm{MPa}$ obtained at CT of

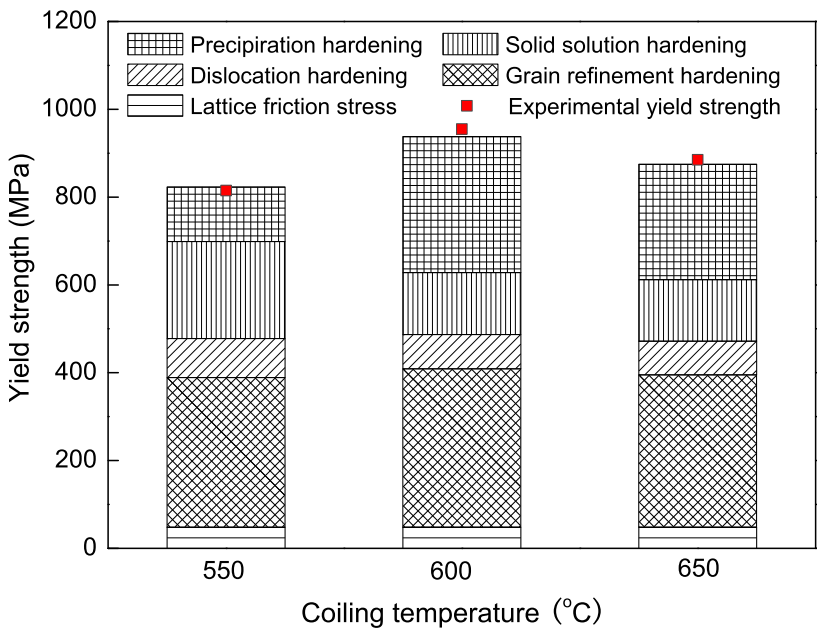

Fig. 6 Comparison of YS between the experimental results and the predictions with Eq. (1) for the steel at different CTs

$620{ }^{\circ} \mathrm{C}$ of $0.08 \mathrm{C}-1.7 \mathrm{Mn}-0.17 \mathrm{Ti}-0.27 \mathrm{Mo}$ steel [12] by the identical TMCP schedule. This may be attributed to the addition of microalloying element $\mathrm{V}$, and Jha et al. [11] had got the same point through the comparison of a steel containing $\mathrm{V}$ and the other steel containing no V. Moreover, the amount of alloy elements in solution is significantly decreased at $\mathrm{CT}$ of $600{ }^{\circ} \mathrm{C}$, particularly the amount of carbon content in solution. From Eq. (2), it can be seen that the solid solution hardening stress mainly depended on the content of carbon in solution. However, the mass fraction of carbon of the sum of $M \mathrm{C}$ and $M_{3} \mathrm{C}$ at $\mathrm{CT}$ of $550{ }^{\circ} \mathrm{C}$ is much less than that at $\mathrm{CT}$ of $600{ }^{\circ} \mathrm{C}$ (Table 2). This leads to a smaller value of solid solution hardening of sample with $\mathrm{CT}$ of $600{ }^{\circ} \mathrm{C}$ in comparison with that of sample with CT of $550{ }^{\circ} \mathrm{C}$. However, the good combination of grain refinement hardening and precipitation hardening resulted in the high strength of the sample with $\mathrm{CT}$ of $600{ }^{\circ} \mathrm{C}$.

At the higher $\mathrm{CT}$ of $650{ }^{\circ} \mathrm{C}$, the diffusivity of $\mathrm{Ti}, \mathrm{V}$ and Mo has been enhanced and they combine with Carbon more easily, which makes $M C$ carbides precipitated more sufficiently compared with that of the sample with CT of $600{ }^{\circ} \mathrm{C}$ (Table 2). The dislocation hardening increment between 
sample with CT of $600{ }^{\circ} \mathrm{C}$ and sample with CT of $650{ }^{\circ} \mathrm{C}$ are comparable to each other. Nevertheless, the DSD of sample with CT of $650{ }^{\circ} \mathrm{C}$ is slightly lower than that of sample with $\mathrm{CT}$ of $600{ }^{\circ} \mathrm{C}$. This can be explained as follows: The addition of Mo to steel can suppress the annihilation of dislocations at high temperatures and provide more nucleation sites of supersaturated precipitation of carbides in the ferrite matrix [35]. Consequently, in the sample with CT of $650{ }^{\circ} \mathrm{C}$, lots of nanometer precipitates were observed to randomly precipitate on the dislocations and larger quantities of $M C$ precipitates can be attained, which have a significant influence on precipitation hardening.

\section{Conclusions}

1. The best mechanical properties of the newly developed Ti-V-Mo microalloyed hot-rolled high-strength steel sheet were achieved at $\mathrm{CT}$ of $600{ }^{\circ} \mathrm{C}$ : YS of $955 \mathrm{MPa}$, ultimate tensile strength of $1000 \mathrm{MPa}$ and EL of $17 \%$. This presumably resulted from the fine and homogenous ferrite grain and high volume fraction of nanosized precipitates.

2. The precipitation hardening contribution at CT of $600{ }^{\circ} \mathrm{C}$ was estimated to about $310 \mathrm{MPa}$. It is because the amount of nanometer precipitates is large and precipitates in the diameter from 1 to $10 \mathrm{~nm}$ which occupies $82 \mathrm{wt} \%$.

3. Fine ferrite grain $(\sim 2.5 \mu \mathrm{m})$ was obtained, which can provide a strengthening contribution about 340-360 MPa.

4. The novel steel can be strengthened by a solid solution of different alloying elements, fine grain size of ferrite microstructure and nano-sized carbide particles. However, the variation of precipitation hardening is the main reason for the changes in YS of different CTs.

5. Although the amount of $M \mathrm{C}$ of sample $650{ }^{\circ} \mathrm{C}$ is larger than that of sample $600{ }^{\circ} \mathrm{C}$, the precipitation hardening contribution of sample $650{ }^{\circ} \mathrm{C}$ is less than that of sample $600{ }^{\circ} \mathrm{C}$. It is attributed to two main reasons: One is that the mass fraction of $M C$ particle with the size $<10 \mathrm{~nm}$ of sample with $\mathrm{CT} 650{ }^{\circ} \mathrm{C}$ is less than that of sample $600{ }^{\circ} \mathrm{C}$ and the another is that $M \mathrm{C}$ particles coarsened at higher $\mathrm{CT}$ of $650{ }^{\circ} \mathrm{C}$.

Acknowledgments This work was financially supported by the National Basic Research Program of China (No. 2010CB630805), the National Natural Science Foundation of China (No. 51201036) and China Iron \& Steel Research Institute Group (No. 12060840A).

\section{References}

[1] Z.B. Jiao, C.T. Liu, Mater. China 30, 6 (2011) (in Chinese)

[2] Y. Gan, H. Dong, China Metall. 8, 1 (2004) (in Chinese)
[3] T.Y. Hsu, Shanghai MET 31, 1 (2009) (in Chinese)

[4] W.C. Leslie, The Physical Metallurgy of Steels (McGraw-Hill, New York, 1981)

[5] K.B. Kang, O. Kwon, W.B. Lee, C.G. Park, Scr. Mater. 36, 1303 (1997)

[6] H. Ohtska, M. Umemoto, I. Tamura, in Proceeding of International Conference on Thermec 88 (ISIJ, Tokyo, Japan, 1988), pp. $352-359$

[7] A. Bakkaloglu, Mater. Lett. 56, 263 (2002)

[8] I. Tamura, H. Sekine, T. Tanaka, C. Ouchi, Thermomechanical Processing of HSLA Steels (Butterworth and Company, London, 1988)

[9] Y. Funakawa, T. Shiozaaki, K. Tomita, T. Yamamoto, E. Maeda, ISIJ Int. 44, 1945 (2004)

[10] Y.F. Shen, C.M. Wang, X. Sun, Mater. Sci. Eng., A 528, 8150 (2011)

[11] G. Jha, S. Das, S. Sinha, A. Lodh, A. aldar, Mater. Sci. Eng., A 561, 394 (2013)

[12] Y.W. Kim, S.W. Song, S.J. Seo, S. Hong, C.S. Lee, Mater. Sci. Eng., A 565, 430 (2013)

[13] D.B. Park, M.Y. Huh, J.H. Shim, J.Y. Suh, K.H. Lee, W.S. Jung, Mater. Sci. Eng., A 528, 560 (2013)

[14] C.Y. Chen, H.W. Yen, F.H. Kao, W.C. Li, C.Y. Huang, J.R. Yang, S.H. Wang, Mater. Sci. Eng., A 499, 162 (2009)

[15] H.W. Yen, C.Y. Huang, J.R. Yang, Scr. Mater. 61, 616 (2009)

[16] I.B. Timokhina, P.D. Hodgson, S.P. Ringer, R.K. Zheng, E.V. Pereloma, Scr. Mater. 56, 601 (2007)

[17] J.H. Jang, C.H. Lee, Y.U. Heo, D.W. Suh, Acta Mater. 60, 208 (2012)

[18] F.B. Pickering, B. Garbarz, Mater. Sci. Technol. 5, 227 (1989)

[19] Q.L. Yong, Secondary Phases in Steels (Metallurgy Industry Press, Beiing, 2006) (in Chinese)

[20] R.X. Jia, Y.M. Zhang, Y.M. Zhang, H. Guo, Spectrosc. Spectr. Anal. 30, 1995 (2010)

[21] D.L. Li, J.F. Fang, Q.B. Liu, C.F. Liu, J.Y. Zhang, Metall. Anal. 28, 1 (2008) (in Chinese)

[22] Y.C. Chih, C.C. Chien, R.Y. Jer, Mater. Charact. 88, 69 (2014)

[23] J.H. Jang, Y.U. Heo, C.H. Lee, H.K.D.H. Bhadeshia, D.W. Suh, Mater. Sci. Technol. 29, 309 (2013)

[24] W. Oldfield, ASTM Standardization News (ASTM, West Conshohocken, PA, 1975), pp. 24-29

[25] Q.L. Yong, M.T. Ma, B.R. Wu, Microalloyed Steel-Physical and Mechanical Metallurgy (China Machine Press, Beijing, 1989), p. 65 (in Chinese)

[26] F.R. Nabarro, Theory of Crystal Dislocations (Oxford University Press, London, 1967)

[27] Y.W. Kim, S.G. Hong, Y.H. Huh, C.S. Lee, Mater. Sci. Eng., A 615, 255 (2014)

[28] Y.W. Kim, J.H. Kim, S.G. Hong, C.S. Lee, Mater. Sci. Eng., A 605, 244 (2014)

[29] Z.C. Liu, H.P. Ren, Diffusion Transformation of Supercooled Austensite (Science Press, Beijing, 2007) (in Chinese)

[30] Q.D. Liu, J.C. Peng, W.Q. Liu, B.X. Zhou, Acta Metall. Sin. 45, 1288 (2009) (in Chinese)

[31] B. Ghosh, C.E. Cambell, G.B. Olson, Metall. Mater. Trans. A 30, 501 (1999)

[32] T.P. Wang, F.H. Kao, S.H. Wang, J.R.J.P. Yang, C.Y. Huang, H.R. Chen, Mater. Lett. 65, 396 (2011)

[33] R.W.K. Honeycombe, Metall. Sci. 14, 201 (1980)

[34] Q.L. Yong, L. Zheng, Acta Metall. Sin. A 20, 9 (1984) (in Chinese)

[35] W.B. Lee, S.G. Hong, C.G. Park, K.H. Kim, S.H. Park, Scr. Mater. 43, 319 (2000) 